\title{
Maintenance Testing of Sprinkler Heads: Qualitative Analysis Causes of Failures
}

\author{
SERGE ZHUIYKOV, Ph.D.* and VINCE DOWLING \\ *Materials Scientist \\ CSIRO, Manufacturing and Infrastructure Technology \\ Industrial \& Research Services \\ 37 Graham Rd. \\ Highett, Victoria 3190, Australia
}

\begin{abstract}
Thousands of sprinkler heads, which have been sampled from in-service sprinkler systems, were tested by Fire Systems Group (FSG) of Industrial \& Research Services (IRS) of CSIRO in accordance with the requirements of Australian Standard AS 1851: Part 3 (Maintenance of fire protection equipment - Automatic fire sprinkler systems) and SSL Test Specification FTS-123. During the course of this testing FSG investigated causes of test failures of the sprinkler head samples. The results of these investigations indicated that the main reasons for failure of used sprinkler heads were: adding sodium silicate ("waterglass" or "egg preserver") to the system in order to overcome small leaks; "intergranular" corrosion of the lead-tin-bismuth "eutectic solder," which fastens together the two halves of the fusible link; extensive deposit of paint on the deflector and the glass bulb or fusible link; heavy build-up of dirt and debris on the frame, heat-sensitive element and deflector; adhesion of the orifice disc to its seat, due to "glue-like" deposits of corrosion product; and deep deposits of hardened sediment or heavy build-up of water hardness salts above the orifice disc.
\end{abstract}

KEYWORDS: automatic sprinkler systems, sprinkler heads, maintenance testing

\section{INTRODUCTION}

In recent years, lack of comprehensive Australian sprinkler failures statistics appears to have been a significant hindrance to those involved in the development of new sprinkler heads. The Australian insurance industry previously had a system for collation of detailed sprinkler system performance statistics, and other loss information, but it appear to have fallen into disuse. General sprinkler statistics from Australia and New Zealand covering the period 1886 to 1986 [1,2] suggested that four or fewer sprinklers controlled 89.7\% of all of the studied sprinklered fires. However, it is impossible to find statistics covering the likely or actual causes of sprinkler head failure, despite one's expectation that such statistics should be disseminated widely throughout the fire protection community. It is therefore imperative that currently-available sprinkler failure statistics now be collated and made available to sprinkler system designers, so that they will avoid specification of sprinkler heads having constructional or design features which are likely to be prone to failure.

The automatic sprinkler itself, often referred to as the "sprinkler head", is the key component of the sprinkler system [2,3]. Most sprinkler system designers prefer to specify "listed" sprinkler heads basically because the statistical records of "listed" sprinklers shown that they can be expected to reliably operate in a severe fire. This is simply due to the fact that one of the design objectives of the sprinkler head manufacturer is to achieve control in $99 \%$ of all sprinklered fire incidents, within the limits of the 
resulting system designs [1,4]. In fact, a study of more than 9000 fires in buildings with sprinklers in Australia and New Zealand has indicated that the sprinklers operated successfully in $99.5 \%$ cases [5]. However, the same report is also indicated that as many as $90 \%$ of sprinkler systems in building were faulty but were being signed off as safe in New Zealand. Therefore, it is inevitable that the appropriate maintenance of sprinkler systems is inseparably connected with the reliability of sprinkler systems.

Term “listed" is defined as sprinkler equipment or materials demonstrated to meet appropriate Standards or which have been tested in a specified manner and found suitable for the intended use [3]. Various organisations produce lists of equipment which they have deemed to be suitable for use in fire sprinkler systems. The means for identifying listed equipment may vary with each organisation concerned with product evaluation. Some organisations do not recognise equipment as listed unless it is also labeled as such, including the organisation's listing mark and the equipment's listing reference number. For guidance on properly identifying and nominating a product as listed, reference should be made to the method used by the organisation which has listed the equipment in question.

IRS is a business unit of the Commonwealth Scientific Industrial Research Organisation (CSIRO) and is responsible for conducting investigations and the testing of fire protection equipment and suppression systems on behalf of the ActivFire Listing Scheme. The ActivFire Scheme lists systems and individual equipment items that are deemed to comply with the Australian and International Fire Safety Standards. The protection of the community through the maintenance and administration of a suite of the ActivFire Scheme is one of CSIRO's most important roles. FSG is accredited by the National Association of Testing Authorities, Australia (NATA) for testing of fire-protection equipment as required by the relevant Australian and International Standards. FSG has been testing used sprinkler heads in accordance with the requirements of Australian Standard AS 1851: Part 3 [6] since 1992. In doing so, thousands of used sprinkler head samples have been tested by FSG. During the course of this testing FSG of IRS also investigated causes of the test failures of the sprinkler heads [3,7]. The results of these failure investigations strongly illustrate the importance, to satisfactory design and develop new sprinkler heads, along with continuing this valuable sprinkler test and investigation work, and the publishing of the resultant statistical and qualitative information. In this paper, we have focused our attention on the probable, or actual, causes of the failures of the CSIRO-tested used sprinklers.

\section{DETAILS OF CSIRO'S SPRINKLER HEAD TESTING}

\section{NATA Accreditation}

Based on the fact that AS 1851.3 does not specify the actual test procedures to be used, FSG, in consultation with NATA, has developed the test procedures that are specified in Test Specification FTS-123 [8]. This test procedure specifies the number of tests required for maintenance testing of used sprinkler heads. SSL, the predecessor of IRS, then gained NATA Accreditation for performing the FAS-123 [8] test procedures and has been maintaining this accreditation up to now. FAS-123 [8] testing practices have been regularly audited by NATA. The FAS-123 [8] procedures are based as closely as possible on those of AS 1851.8 [9], which are for the purpose of "type testing" of unused sprinkler head samples as part of a listing investigation. 


\section{Numbering and Visual Inspection of Samples}

Each sprinkler submitted for testing was marked with an identifying number. Visual inspection of sprinklers was made to quantify legibility of markings, external oxidation, build-up of dirt and grease and internal deposits of foreign matter within the orifice which may reduce or obstruct water flow and compromise effective operation.

\section{Hydrostatic Leakage Testing}

After the visual inspection, sprinklers should be mounted in the pending position in the hydrostatic test apparatus (manifold) as shown in Fig. 1a.

The pressure was increased at an average rate of $100 \mathrm{kPa} / \mathrm{sec}$ to the test pressure of 3500 $\pm 100 \mathrm{kPa}$. To pass this test sprinkler heads should allow permissible leakage 0 millilitres per minute at the test pressure $3500 \pm 100 \mathrm{kPa}$ for $3 \mathrm{~min}$.

\section{Division of the Sample Batch}

Following the hydrostatic leakage test, the batch of sprinklers is divided into two. At this stage, half the sprinkler heads are subjected to a function test. This test is designed to check for correct release and unobstructed spray pattern. The other half of the batch is subjected to an operating temperature test which checks the release temperature.

\section{Functional Testing}

Sprinkler heads for functional testing were installed in their normal mounting position in a test chamber (see Fig. 1b) and connected to pipes that were then pressurised with water to $35 \pm 5 \mathrm{kPa}$. The sprinkler's heat-sensitive element was then actuated by means of a jet of hot air. To pass this test, normal discharge must commence immediately on actuation and, during the following 60 seconds, the distribution pattern must suffer no interference from hang-ups or "lodgements." Figure 2 illustrates the required interference-free water flow pattern. After the test each sprinkler head was inspected for lodgements at the end of the water flow period and before removal from the chamber.

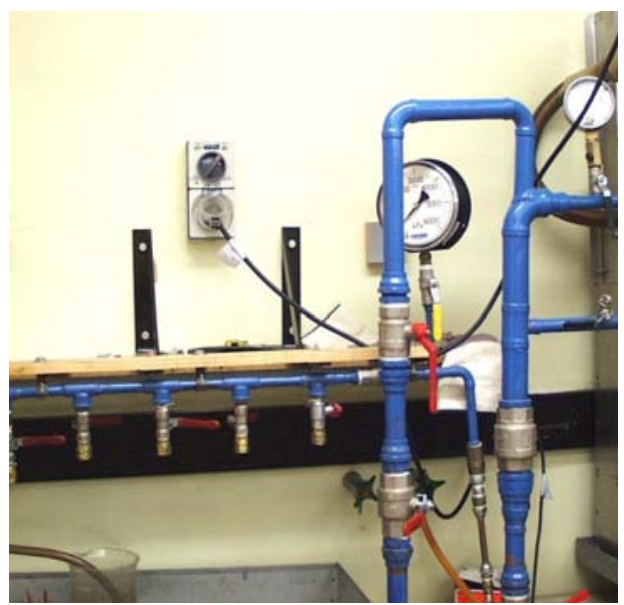

(a)

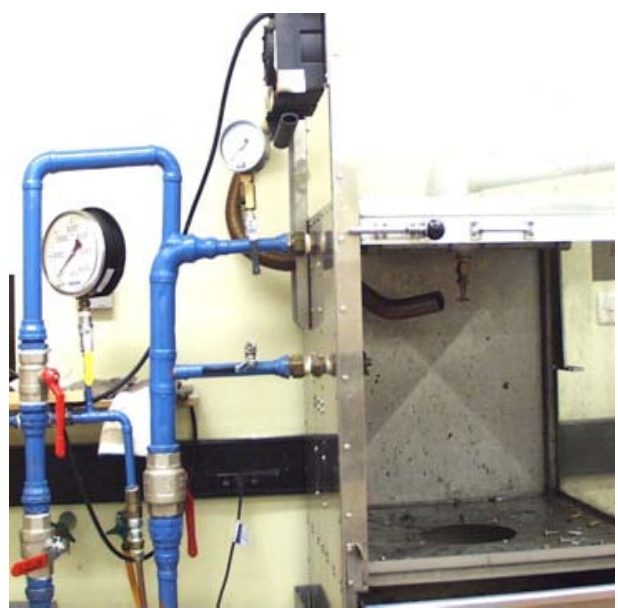

(b)

Fig. 1. Sprinkler heads test apparatus. 


\section{Operating Temperature Test}

The Operating Temperature Test was designed to check the operating temperature of the heat-sensitive elements of the sample sprinkler heads. All tests were carried out in an ambient temperature of $25^{\circ} \mathrm{C} \pm 5^{\circ} \mathrm{C}$.

A heated liquid bath was utilised to bring the sprinklers under test to their operating temperature. Distilled water was used for sprinklers of nominal operating temperature not exceeding $68^{\circ} \mathrm{C}$. In accordance with the requirements of FTS-123 [8], to pass this test, the glass bulb sprinklers should be operated within the temperature range specified in the Table 1.

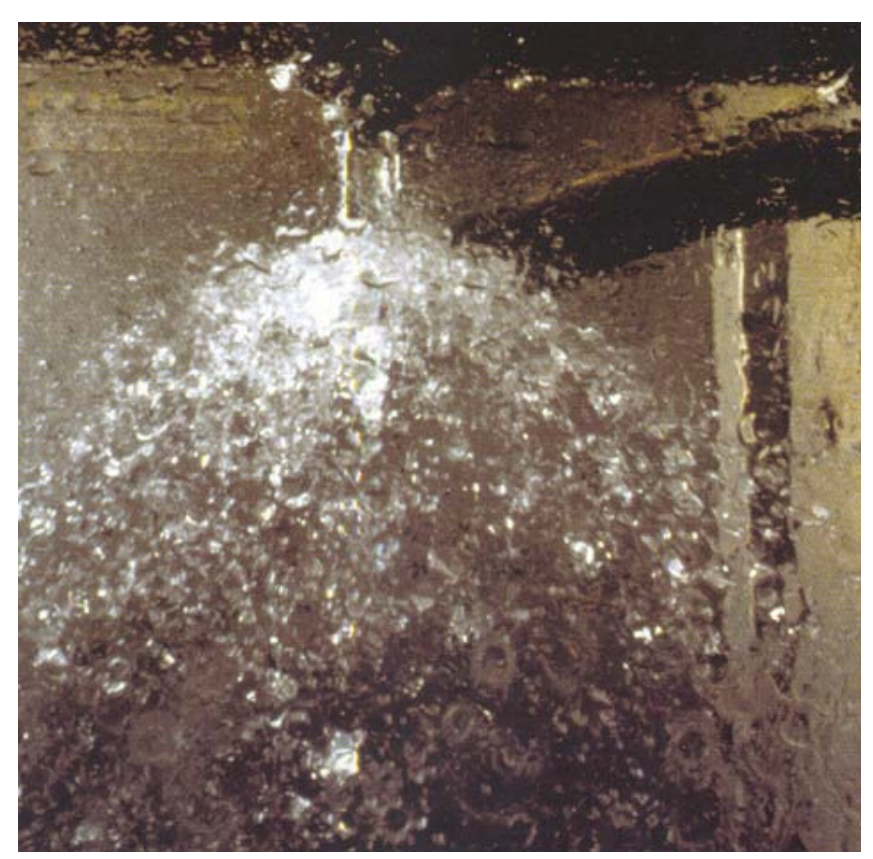

Fig. 2. Example of the functional test of the sprinklers.

Refined oil was used for sprinklers of nominal operating temperatures up to $300^{\circ} \mathrm{C}$. The temperature was raised at a constant controlled rate of $0.55^{\circ} \mathrm{C} / \mathrm{min} \pm 0.15^{\circ} \mathrm{C} / \mathrm{min}$ until operation of the sprinklers. In the case of glass bulb sprinklers, the operation is defined as any form of rupture of the bulb envelope.

In the case of fusible-element type sprinklers, FTS-123 [8] requires that they shall operate within a temperature range of

$$
\mathrm{t} \pm(\mathbf{0 . 0 3 5 t}+\mathbf{0 . 6 2})^{\circ} \mathrm{C}
$$

where $\mathbf{t}$ is the normal operating temperature $\left({ }^{\circ} \mathrm{C}\right)[8]$.

The measurement of orifice diameter of the sprinklers was performed after their removal from the operating temperature test bath, or from the function test chamber, and allowing them to stabilise at room temperature for at least 15 minutes. 
Table 1. Operating temperature range for glass bulb sprinklers.

\begin{tabular}{|ccc|}
\hline $\begin{array}{c}\text { NOMINAL OPERATING } \\
\text { TEMPERATURE } \\
{ }^{\circ} \mathrm{C}\end{array}$ & $\begin{array}{c}\text { LOWEST } \\
\text { TEMPERATURE } \\
{ }^{\circ} \mathrm{C}\end{array}$ & $\begin{array}{c}\text { HIGHEST } \\
\text { TEMPERATURE }\end{array}$ \\
\hline 57 & 54 & 74 \\
\hline 68 & 65 & 86 \\
\hline 79 & 76 & 99 \\
\hline 93 & 90 & 113 \\
\hline 100 & 97 & 120 \\
\hline 121 & 118 & 141 \\
\hline 141 & 138 & 163 \\
\hline 163 & 160 & 186 \\
\hline 182 & 179 & 206 \\
\hline 227 & 224 & 252 \\
\hline 260 & 257 & 286 \\
\hline & & \\
\hline
\end{tabular}

\section{RESULTS AND DISCUSSION}

Australian Standard AS 1851.3 requires pressure and operating characteristics testing of representative samples of all sprinklers in a system after 24 years in service, and then at six-year intervals thereafter. However, many very old sprinklers have passed the testing because they had apparently been installed and maintained in environments where they had not been subjected to abnormal conditions, such as corrosion, abnormally high temperatures or mechanical abuse. Some of the sprinkler head types, which have been tested since 1992, are shown in Fig. 3.

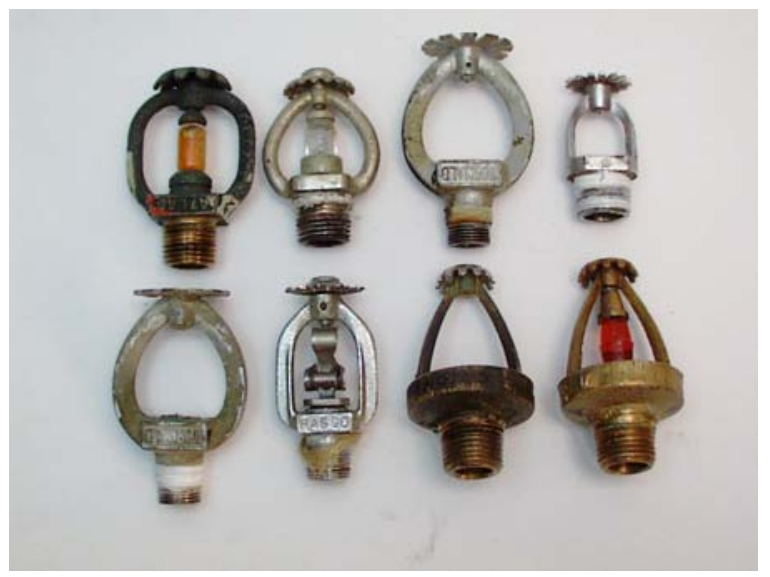

Fig. 3. Examples of the sprinkler heads tested. 


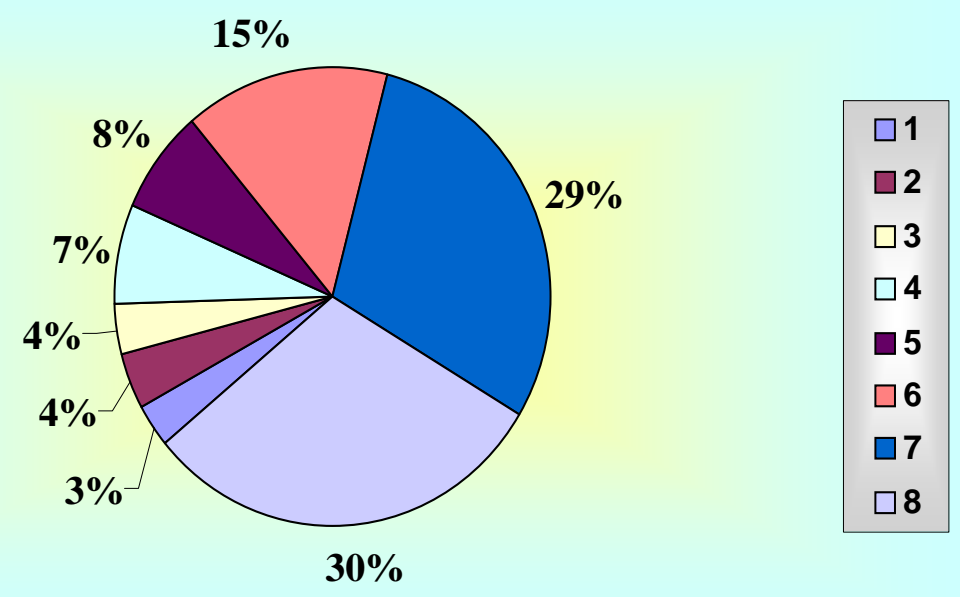

Fig. 4. Comparison of different failures for the Sprinkler Heads:

1 - "O-ring adhesion" of the sprinkler head; 2 - Undetected rupture of bulb wall; 3 -

Systems "dosed" with sodium silicate in order to overcome small leaks; 4 - Heavy deposits of hardened sediment; 5 - Heavy build-up of dirt and debris on the frame, heatsensitive element and deflector; 6 - "Intergranular" corrosion of the lead-tin-bismuth "eutectic solder"; 7 - Unlisted sprinkler heads; 8 - Extensive deposit of paint on the deflector and the glass bulb or fusible link.

500 failures among 6350 sprinkler heads tested during last few years have been analysed. Comparison of different types of failure for 500 investigated sprinkler heads failures is shown in Fig. 4. In many protected commercial properties, conditions exist that cause an accumulation of foreign material on automatic sprinklers so that operation of the sprinkler may be retarded or prevented. This condition is commonly called "loading" [7]. Any accumulation of foreign material on sprinklers tends to retard their operation as a result of the heat-insulating effect of the loading material. If the deposit is hard, it may physically retard or prevent the sprinkler from operating. Unless cleaning is done very carefully, deposits are likely to accumulate to such an extent as to interfere seriously with sprinkler operation. During our testing of the used sprinkler heads we found that, when they are subjected to the Operating Temperature Test, a high proportion of "fusible link" type heads ( $15 \%$ among 500 heads) failed to release either when the maximum allowable release temperature was reached or when the maximum test bath temperature was reached. This problem is invariably caused by "intergranular" corrosion of the leadtin-bismuth "eutectic solder" which fastens together the two halves of the fusible link. Such corrosion occurs when the heads are serving an area that is or was formerly regularly contaminated by acidic fumes such as those resulting from pickling and electroplating processes.

Some types of sprinklers are less susceptible than others to corrosive conditions. Nonferrous metal is used for sprinkler parts, but special protective coatings are necessary for all types exposed to extreme corrosive conditions. Approved corrosion-resistant or 
special coated sprinklers are needed in locations where chemicals, excessive moisture, or corrosive vapours exist.

During our testing it is estimated that about $8 \%$ of the 500 failure sprinkler heads were found to have severely obstructed orifices due to heavy deposits of hardened sediment, or heavy build-up of water hardness salts, above the orifice disc. These heads usually fail the functional test due to failure of the seal disc to unseat, or to providing very distorted reduced-flow spray pattern. One of the examples of sprinkler head with extensive corrosion is shown in Fig. 5.

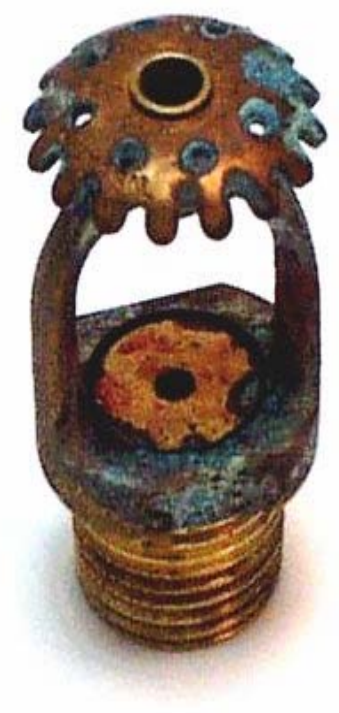

Fig. 5. Typical example of severe orifice seal corrosion of the sprinkler head.

Interestingly, the corrosion of this sprinkler was so severe that the orifice seal did not dislodge during the functional testing at pressure of $35 \mathrm{kPa}$ after glass bulb eruption at $70^{\circ} \mathrm{C}$.

Where sprinklers are subject to loading (accumulations of foreign material) or corrosion, perhaps only to a moderate or slight extent, they should be examined carefully and frequently. If the condition of sprinklers appears doubtful, a representative sample (six or more) should be removed, carefully packed to avoid damage in transit, and sent to an appropriate testing laboratory or to the sprinkler manufacturer. The results of their testing will indicate the condition of similar sprinklers remaining in the property.

Another common defect of sampled sprinkler heads is a heavy build-up of dirt and debris on the frame, heat-sensitive element and deflector. This causes delayed release and, if the deflector deposit is adhering strongly, a very uneven spray pattern. All sprinkler heads affected in this manner should urgently be carefully cleaned or, if this is not possible, replaced with suitable new sprinkler heads.

The best practice is to replace loaded sprinklers with new sprinklers rather than to attempt to clean them. Attempts at cleaning, particularly in instances where deposits are hard, are likely to damage the sprinkler, rendering it inoperative or possibly causing leakage. Water-soluble cleaning liquids of caustic or acid type are likely to be destructive to 
sprinklers and should not be used for cleaning. No hot solution of any kind should be used.

During the course of maintenance testing, FSG found that about 30\% of the 500 failures were sprinkler heads with extensive deposits of paint, as shown in Fig. 6, or were completely paint-covered. When tested for operating temperature, these heads were invariably found to release well above the maximum allowable temperature. Paint-fouled deflectors were observed to severely degrade the spray pattern, when a functional test was performed. This defect translates to inadequate area coverage in a true fire situation, and a high likelihood of fire over-run of the sprinkler system. Those painted sprinkler heads, which shown in Fig. 6, failed to dislodge their orifice seals during functional test for 5 minutes.

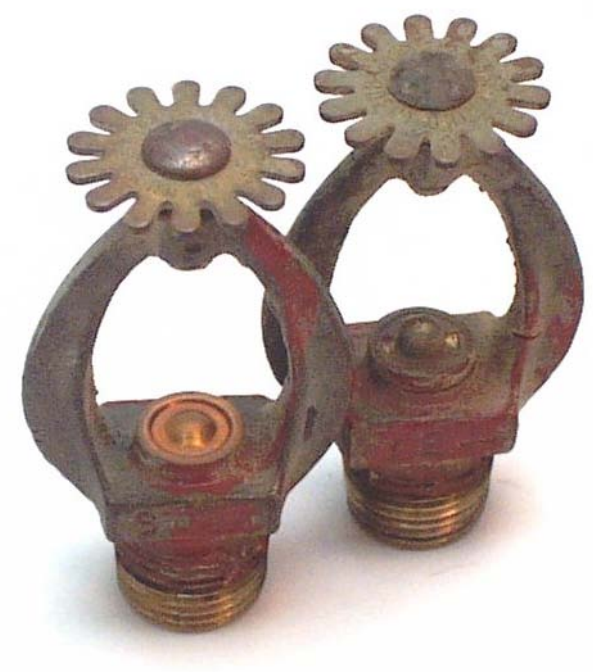

Figure 6. Examples of painted sprinkler heads

There is no known method whereby paint under the seal-disc or on the fusible link can be removed adequately. Sprinklers that have been painted by anyone but the manufacturer must urgently be replaced with new units.

Obstructions in system piping will reduce or cut off the flow of water from a part or all of the system and will not give the protection intended. Obstruction of piping is one of the well-known and well-recognised causes of unsatisfactory sprinkler performance. One source of obstruction is foreign material in the water-supply system, and another is foreign material originating within the system piping itself.

Scale, corrosion and incrustations can also form in the piping. Deep well water containing natural salt tends to corrode pipe interiors, and the piping of wet systems may be found obstructed by rust and corrosion. Obstructing material is carried into piping when systems operate or are refilled after draining. It may plug one or more fittings or obstruct a number of sprinklers at the end of the system. Pipe capacities may be reduced by incrustation where water contains lime or magnesia. 
$4 \%$ of the 500 failures were sprinkler heads which had been "dosed" with sodium silicate ("waterglass" or "egg preserver") in order to overcome small leaks. In such cases, the orifice discs of the heads that were "weeping slightly" became "glued" to the seal seat, and will not release at anywhere near the required minimum system design pressure of $35 \mathrm{kPa}$. These sprinkler heads failed the functional test. Typical example of this failure is shown in Fig. 7. Systems with heads affected in this manner are likely to be over-run by a fire, resulting in greatly increased property damage and financial loss.
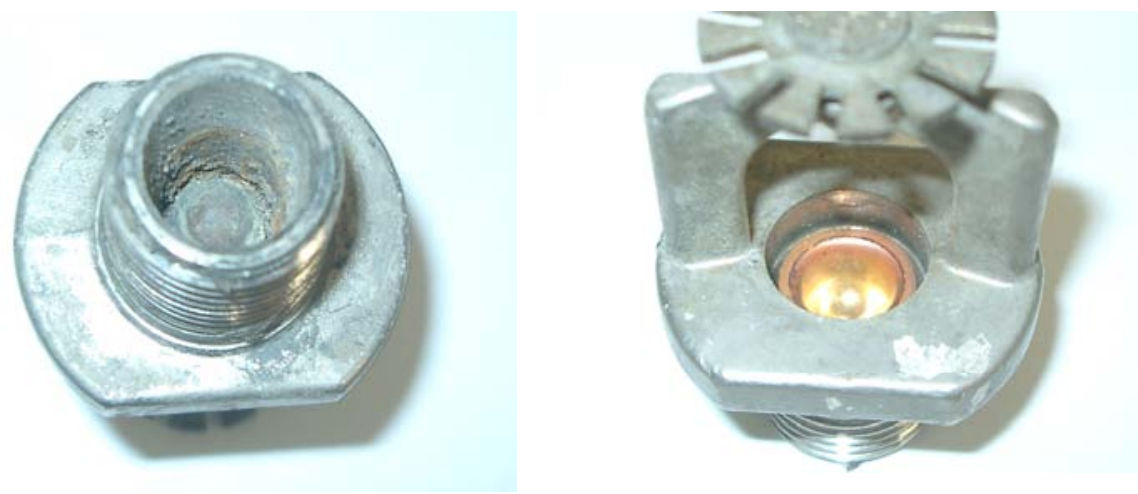

Fig. 7. Example of sprinkler head dosed with sodium silicate in order to overcome small leaks.

In addition to such failures as described above, FSG encountered samples of sprinkler heads which fail to activate due to apparently undetected rupture of the bulb wall. Approximately 4\% among 500 failures were glass bulb type sprinkler heads which were found to have empty or partly empty bulbs. Examples of these ruptures are shown below. Figure 8a shows that the glass bulb had been accidentally broken but the sprinkler did not activate. In the second case (Fig. 8b), the bulb cracked and allowed the liquid inside to drain completely away without releasing water. These samples were taken from separate sprinkler systems which appeared to be fully operational.

In the event of a fire occurring, neither of these sprinkler heads would have activated. The danger is that if this was to occur in a critical location, the fire may spread through a larger area than it might otherwise have done. Equally, the fire hazard (smoke/toxic fumes) may reach a level hazardous to building inhabitants.

Sprinkler heads with the above type of defect shown in Fig. 8 will often pass the hydrostatic leakage test, but will always fail the operating temperature test and function test. When closely examined, these bulbs are generally found to be made of ordinary glass, rather than the much more reliable "quartzoid" type glass now always used, and the wall thickness is always found to be very uneven and, in places, extremely thin. Many "non-quartzoid" bulbs have failed the operating temperature test (usually by opening at too high a temperature) or the functional test (due to a large glass fragment remaining "bridged" between the orifice disc and the adjusting screw, or lodging on the deflector). Most, if not all, "non-quartzoid" heads have been found to have never been listed. Building owners should ensure that their glass-bulb sprinkler heads are not of the "nonquartzoid" type. All heads of this type that are discovered during system inspection should be replaced without delay. Importance of the regular inspection and testing the heads of old sprinkler systems is clearly demonstrated by these two examples discussed above. 


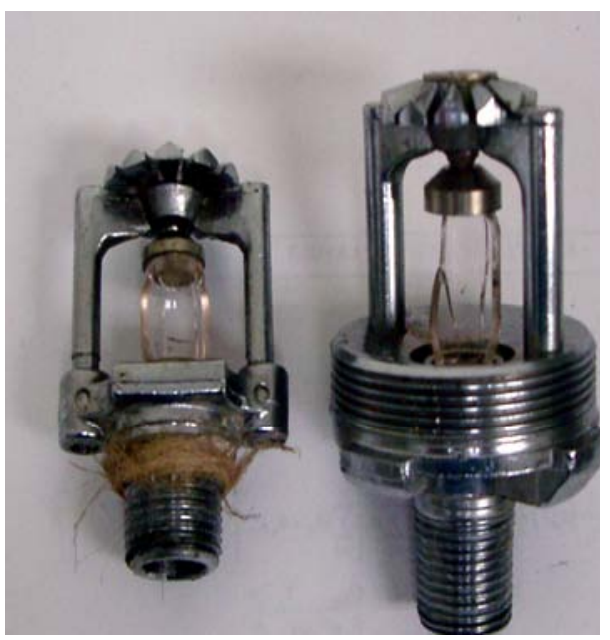

(a)

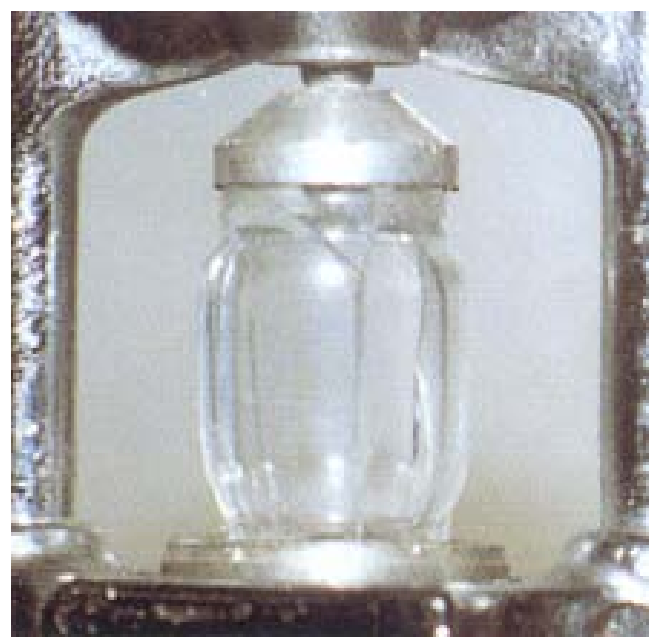

(b)

Fig. 8. Examples of undetected rupture of glass bulb.

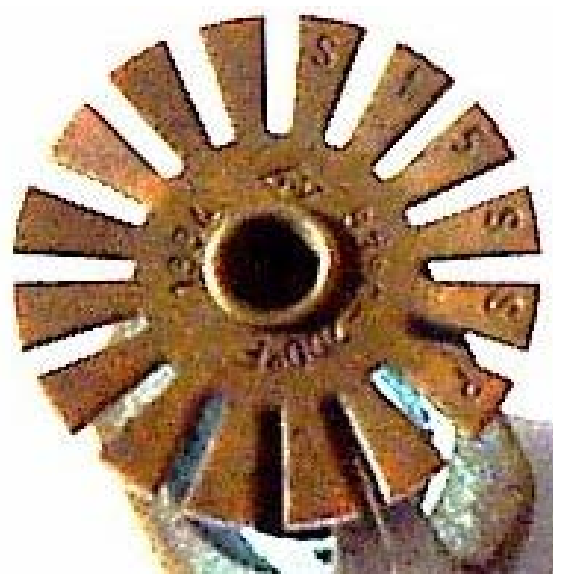

(a)

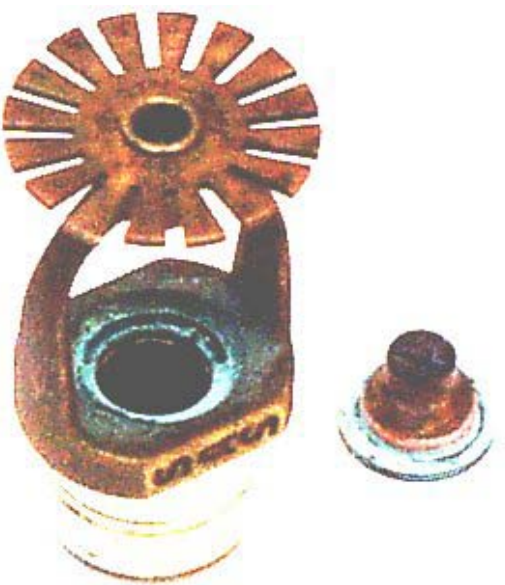

(b)

Fig. 9. Example "O-ring adhesion” of the sprinkler head.

A small number of FSG's sprinkler test failures have involved an orifice plug which is sealed by means of a small O-ring which sits in a groove in the plug's cylindrical surface and is pressed ("radially-squeezed") into contact with the wall of the outlet end of the sprinkler orifice. Release of the plug requires the water pressure to act on the "tail" of the plug such that sufficient longitudinal thrust is developed to cause the compressed O-ring to slide along the orifice bore, in a similar fashion to the piston ring of an engine. During the Function Test, this design of orifice plug has often failed to dislodge, or even to move slightly, after the heat-sensitive element has actuated and cleared away. Hydrostatic pressures of 5 to 10 times the maximum allowable Function Test pressure have been needed to unseat these plugs. On close investigation of the orifice and plug, the cause of the functional failure has mostly been shown to be a phenomenon known as "O-ring adhesion." Some of the FSG test failures of this type appeared to be caused by a 
"microscopic" ridge of salt-like deposit or corrosion product on the orifice bore, at the point of contact of the O-ring, rather than by "O-ring adhesion." It is clear that there is an urgent need for sprinkler listing organisations to develop new test procedures for detecting any tendency towards sprinkler failure of the "plug adhesion" nature, particularly where a manufacturer has submitted a head which has an unusual orifice seal design. A typical example of such a design is shown in Fig. 9. This sprinkler head was only 9 years old at the time of the testing and, as clearly visible from the Fig. 9a, it was made in 1994 and was type-Approved by Factory Mutual Research Corporation (FM). The FM Approval implies that, at the time of the investigation and compliance testing by FM, this type of sprinkler head passed all necessary tests in order to be approved by FM and to be identified by the FM Approval mark.

During FSG's testing of used sprinkler heads it was found that approximately $29 \%$ among 500 failures were the different types of sprinkler heads which had never been listed. Their lack of listing marks was conclusive evidence of this. All listed heads have been subjected to rigorous and very appropriate type testing, which provides a high level of assurance that they will perform reliably provided that they have been correctly installed and maintained. Building owners should therefore urgently check that their sprinkler heads carry valid listing marks, and should replace those that do not with suitable new listed heads.

\section{CONCLUSION}

This paper has perhaps given you only a glimpse of what FSG, by its extensive commercial sprinkler testing experience, has learnt about modes of sprinkler test failure, and how these relate to how defective sprinklers may fail in a real fire situation. We also hope that the information about the failures of sprinkler heads in fire suppression systems has given you an awareness of the need for timely and regular sampling and testing of sprinkler heads of existing sprinkler installations, in order to detect the presence of actually or potentially defective sprinkler heads. The importance of early detection and prompt discarding of non-listed, non-quartzoid, or design-deficient sprinkler heads can not be over emphasized. Building owners or insurers should consider engaging a suitably-experienced consulting engineer to inspect their sprinklered premises for the presence of such dubious heads.

Fire sprinklers have a vitally important role to play in protecting lives and property from the effect of fire, but they will not perform this vital role adequately if they do not receive regular skilled maintenance, including the periodic head sampling and testing described in this manuscript.

\section{REFERENCES}

[1] Stephens J., "Practical Advantages," Fire Engineering Journal \& Fire Protection, 26: No.3, 59-63, (2003).

[2] Marryatt H.W., Fire: A Century of Automatic Sprinkler Protection in Australia and New Zealand 1886 - 1986, Australian Fire Association, 1988, 478 p.

[3] Australian Standard AS 2118 - 1999, "Fire Sprinkler Systems; Part 1.1: Components - Sprinklers and Sprayers,” 1996, Standards Australia, 48 p.

[4] Mountford S., “A Sprinkler in the Works," Fire Engineering Journal \& Fire Protection, 26: No.3, 48-49 (2003). 
[5] Kennedy K., "Faulty Sprinklers an Invitation to Tragedy,” New Zealand Herald, February 3, 2005.

[6] Australian Standard AS 1851.3 - 1997, "Maintenance of Fire Protection Equipment - Automatic Fire Sprinkler Systems,” 1985, Standards Australia, $16 \mathrm{p}$.

[7] Zhuiykov S., Everitt J. and Greenhill S., "Investigation of Failures of Sprinkler Heads in Fire Suppression Systems," Proc. 4th Int. Seminar on Fire and Explosion Hazards, Londonderry, 8-12 September 2003, pp. 228-229.

[8] FTS-123, "Fire Sprinkler Head Testing for Fire Protection System Maintenance Programs," Scientific Services Laboratory Specification, Version 1.4, 29-Jan2004, 6 p.

[9] Australian Standard AS 1851.8 - 1987, "Maintenance of Fire Protection Equipment - Automatic Fire Detection and Alarm Systems,” 1987, Standards Australia, $18 \mathrm{p}$. 